\title{
EUROPEAN SPINE JOURNAL MAX AEBI AWARD FOR CLINICAL SCIENCES 2017/2018
}

ORIGINAL ARTICLE

\section{The value of patient global assessment in lumbar spine surgery: an evaluation based on more than 90,000 patients}

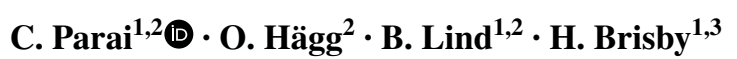

๑) Springer-Verlag GmbH Germany, part of Springer Nature 2019

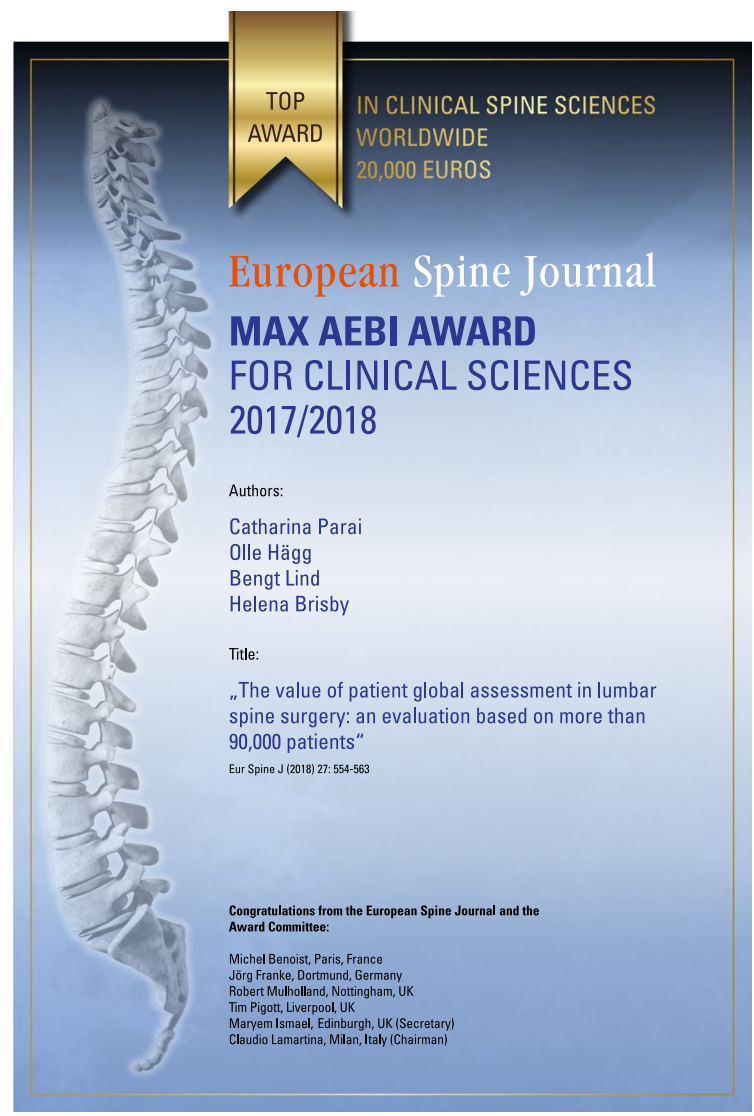

The online version of the original article can be found under https://doi.org/10.1007/s00586-017-5331-0. 